\title{
Nicholas R. Di Luzio, PhD (1926-1986)
}

Dr. Nicholas R. Di Luzio, Professor and Chairman, Department of Physiology at Tu-lane University School of Medicine, died on July 2, 1986, following an extended illness. A gifted scientific investigator and inspiring teacher, Dr. Di Luzio had a distinguished career in biomedical science. He had served previously as Professor and Chairman of the Department of Physiology and Biophysics at the University of Tennessee Medical Units in Memphis. The author of 570 original scientific articles, Dr. Di Luzio had been a motivating force in the establishment of the Reticuloendothelial Society which he served as President. A member and officer of numerous national and international scientific societies, he served as Editor of Advances in Experimental Medicine and Biology.

The many tasks to which he set himself bear witness to his inquiring mind and versatile scientific capabilities. He was dedicated to scientific research and to his students and was greatly respected throughout the international scientific community. His basic biomedical research spanned many areas of investigation, ranging from atherosclerosis to novel and innovative approaches to experimental therapy of neoplasia.

Dr. Di Luzio served with distinction as Editor for Reticuloendothelial System Pathophysiology on the Board of Pathology and Immunopathology Research (formerly Survey and Synthesis of Pathology Research). On behalf of the Board of Editors and the publisher, S. Karger AG, Basel, I express condolences to Dr. Di Luzio's family and host of friends. We shall miss his enthusiasm for scientific investigation, but have a rich heritage in the research accomplishments he has left behind.

Julius M. Cruse 